\section{Existential Intelligence Scale and its Implications for Preliminary \\ Assessment of Ontological \\ Insecurity}

\author{
Shannon J. Fernandes \\ St. Xavier's College \\ shannon.fernandes@xaviers.edu.in
}

\begin{abstract}
This study aims to broaden the view of intelligence beyond the pre-existing notions or categories that include academic-specific domains. The Existential Intelligence Scale (EIS) attempts to measure the extent to which an individual allows themselves to venture into the realm of introspection about elements related to it like death, origins, existence, etc. This scale was made due to the author's dissatisfaction with pre-existing existential scales, The scale was found to be internally consistent and had significant correlations with Depression and Stress on the DASS-21, but not with Anxiety. The limitations and scope for further research are also discussed.
\end{abstract}

\section{Defining Existential Intelligence}

Often intelligence is viewed in a reductionist manner, focusing on an assessment which describes a cognitive process or task, however, the various definitions of intelligence focus on the ability to either adapt or solve problems in the real world (Gardner, H. E., 2011) or deal effectively with the problems we face (Wechsler, D, 1944). Based on these definitions that have hitherto been presented, we can thus deduce the possibility of an existential intelligence, as first proposed by Howard Gardner (2000), as a concept requiring further inquiry and assessment since it tackles with the most primitive problem - the existential and ontological questions surrounding human existence.

These questions could broadly be categorized in sections relating to human origins, death and afterlife, and questions relating to the existence and nature of a deity.

Existential Intelligence, following the above mentioned criteria of intelligence, could simply be defined as "the ability and willingness to tackle problems that are existential in nature". The main keywords of the definition are thus 'ability' and 'willingness'. 'Ability' in relation to 
existential intelligence, relates to the underlying aspect of the human condition that inspires and enables individuals to question their origin or reject existing notions of origin in a postmodern manner, irrespective of the culture or era one lives in. The universality of such a desire in humans is taken as an innate biological or evolutionary device relating to survival in a prima facie manner to dismiss the notion of existential intelligence, however, the existence of a biological or evolutionary or even yet to be discovered neuropsychological reasons in no manner undermines the existence of existential intelligence. Instead, the universality of such a desire points towards a spectrum of existential intelligence, as implied with cognitive intelligence, which is a matter that needs further inquiry.

'Willingness', here, refers to the active implementation of the ability mentioned above. Delusions, dissociations and/or other similar psychopathologies are seen as a split from the actual self by theorists like Laing (1965) when investigating the nature of the self and ontological insecurities that arise. However, the split from the self need not necessarily result in or cause from psychopathologies but instead from a voluntary rejection of skeptical stances towards various existential questions. Religious determination explains this where individuals accept a particular theory of origin, which often involves a deity, even if the theory has no substance in reality. That being said, it should be clarified that this does not in any manner deem religious individuals as unfit for being existentially intelligent.

\section{A Case against Existing Existential Intelligence Scales}

The idea of an existential intelligence scale or existential learner scales isn't completely new as there have been variations of such scales presenting themselves in the past few decades. These scales (Allan, B. A., \& Shearer, C. B., 2012, Amram, Y., \& Dryer, C., 2008) have certain items or elements that do not stand to scrutiny. The aspect of spirituality and religiosity does not fit well into an existential intelligence scale due to its heavy dependence on external or internal reasons. Belief in ghosts or the supernatural need not necessarily be derived from an existential understanding of the world but due to fear or even supernatural oriented education. If belief in the supernatural, like that of ghosts and spirits, were to be counted as an aspect 
under the existential intelligence scale, then it should also be able to include or entertain any amount of conspiracy theories as existential, which would cause it to lose its validity. Moreover, Howard Gardner (2000) also opposes the idea of including spirituality under existential intelligence due to a lack of empirical evidence of the supernatural. He also addresses the person-related aspect of spirituality and finds that it would be best if the phenomenological aspect of spirituality were to be left outside the intellectual sphere.

\section{Ontological Insecurity}

We are introduced to the concept of ontologically security by Laing (1965) which refers to an individual who accepts his/her "presence in the world as real, alive, and in a temporal sense, a continuous person" (Laing. R. D., 1965, p. 39). Thus ontological insecurity occupies an antithetical position from the above mentioned wherein an individual experiences an absence of such assurances, which Laing (1965, p. 39) calls 'primary ontological insecurity', and thus succumbs to the anxiety and other neurotic tendencies. An ontologically insecure individual is threatened by different aspects of life, the threat usually is not a physical one but to the construct of the self. Laing (1965, p. 43) gives the example of a patient who burst out during an argument that he was arguing to preserve his existence. Laing (1965) does not consider the patient to be psychotic but rather ontologically insecure which could result in a threat to the 'self' when in an argument. The ontologically secure individual is not immune to such threats as they too face similar adversities but their sense of self and autonomy is usually independent of the external world, which shields them from the anxiety that arises from such ontological threats. The obliteration or destruction of the 'self' induces immense anxiety in ontologically insecure individuals which could make them dysfunctional and thus our modern cognitive therapies would not be able to deal with such problems due to depth of the problem, as the problem lies on ontological grounds and not irrational thoughts and beliefs. Ontological anxieties could be based on absolutely rational grounds, in which case the therapist does not find proper treatments for the individual, as the individual could be perfectly and yet find it difficult to get about their daily lives. An argument provided against this stands at the roots of the destruction of the 'self'. It would appear that 
there could be underlying reasons behind the fear of such destruction that often arise from childhood or traumas or other aspects that could be treated with the help of cognitive therapies. However, this argument fails to understand the depth of the existential angst generated by ontological insecurity. Smith \& Jones (1993) found that victims of sexual abuse tended to act in a paradoxical manner, contrary to reinforcement theory, wherein they would engage in self-injurious behaviour since it fulfilled the "primitive form of rote' rather than rationally evaluating their behavior. The vulnerable and self-harming behavior had come to form the 'self' for the individual and systematic rationalization of such patients through cognitive therapies would lead to ontological insecurities as it would present them with a threat to the self while attempting to preserve their neophobia (fear of the new in contrast to the primitive rote form). Thus the authors call for a range of treatments that assist different aspects rather than focusing only on cognitive therapies. Thus the current scale being presented acts as a methodical and standardized investigation into existential intelligence. The scale acts as a preliminary assessment of such ontological insecurity.

\section{The Existential Intelligence Scale}

Preliminary Assessment

The Existential Intelligence Scale (EIS) is developed to investigate the extent to which individuals indulge or participate in the existential questions mentioned above. Therefore the questions too differ in terms of the categories it holds, which includes the origins of life, participation in matter relating to death and afterlife, the concept of the self, and the nature and existence of a deity. The scale consisted of 12 items. The scale can be found in the appendix.

Method: Participants were given the existential intelligence scale through an online software used for assessing psychological variables known as Psytoolkit (Stoet, G., 2010, 2017)

Subjects: The preliminary assessment of the existential intelligence scale included 78 participants from which 13 were excluded due to missing values. The subjects were asked to participate in the study through online forums. The participant's age varied from 16 to $36(M=19.97, S D=3.11)$. Results: A preliminary assessment of the scale $(n=65)$ found the scale to have reasonable internal consistency $(\alpha=.80)$.

\section{Table 1 - Preliminary Assessment of the EIS}




\begin{tabular}{ccccc}
\hline Mean & SD & Min & Max & Reliability \\
\hline 35.18 & 7.67 & 20.0 & 48.0 & .80 \\
\hline
\end{tabular}

Correlation with DASS-21

The scale was replicated with a larger sample $(N=114)$ to ensure the reliability and to measure a correlation to other neurotic and psychopathological variables like anxiety, stress and depression using the Depression Anxiety Stress Scales-21 (DASS-21) (Osman, A., Wong, J. L., et al., 2012).

Method: Participants were given the existential intelligence scale through an online software used for assessing psychological variables known as Psytoolkit (Stoet, G., 2010, 2017)

Subjects: The relational study consisted of 140 participants from which 26 were excluded due to missing values. The subjects were asked to participate in the study through online forums. The participant's age varied from 11 to $60(M=$ 23.3, $S D=7.83)$.
Results: The correlation between existential intelligence scale and depression $(\mathrm{r}=.21, \mathrm{p}$ $=.024)$, and stress $(\mathrm{r}=.23, \mathrm{p}=.013)$ were significant at the $\mathrm{p}<.05$ level. While correlation between existential intelligence scale and anxiety $(r=.09)$ was not significant at the $\mathrm{p}<.05$ level.

\section{Table 2 - Replication of the EIS}

\begin{tabular}{ccccc}
\hline Mean & SD & Min & Max & Reliability \\
\hline 33.75 & 9.22 & 2.0 & 48 & .86 \\
\hline
\end{tabular}

\section{Discussion}

It would appear that the scale is internally consistent. The internal validity of the study would appear to be moderate which can be inferred based on both the studies and they are significantly correlated with depression and stress, however, the scale did not show any relation with anxiety. These could be a result of confounding factors and a better design with more control could show a relationship in the future, thus further research is required. The external validity of the study would appear to be low as the sample size was neither adequate nor representative enough to generalize. The experimental realism of the study would 
appear to be moderate as the form presented was short and the incentive of being provided with a score in the end would increase engagement with the form, but the questions inherently do not possess any element that could increase active involvement. Lastly, the mundane realism of the study would appear to be moderate as individuals, especially adolescents (which happens to be the majority of the participants) are used to filling out surveys and forms often.

This is a preliminary study of existential intelligence, a relatively recent area of interest. The implications of the scale are related to clinical practice concerning the ontological nature of anxiety. The anxiety that derives from a high existential understanding of the world needs a psychometric evaluation, one that is objective and standardized, and thus this was an attempt to construct such a test.

A few of the limitations of the study could be the smaller sample size, a larger sample size would have a much better chance of being generalizable. The items in the scale lean towards existential intelligence which would explain the high mean. Thus item analysis would be required for future research to identify and replace the poor items.
The study aimed at emphasizing the importance of ontologically induced anxiety and its effect on individuals. Further research could assess the demographic variables concerning religious affiliation as a lack of belief in a deity could cause ontological insecurity.

\section{References}

Allan, B. A., \& Shearer, C. B. (2012). The scale for existential thinking. International Journal of Transpersonal Studies, 31(1), 21-37.

Amram, Y., \& Dryer, C. (2008, August). The integrated spiritual intelligence scale (ISIS): Development and preliminary validation. In 116th annual conference of the American Psychological Association, Boston, MA (pp. 14-17).

Gardner, H. (2000). A case against spiritual intelligence. The international journal for the psychology of religion, 10(1), 27-34.

Gardner, H. E. (2000). Intelligence reframed: Multiple intelligences for the 21st century. Hachette UK. 
Gardner, H. E. (2011). Frames of mind: The theory of multiple intelligences. Hachette Uk.

Laing, R. D. (1965). The divided self: An existential study in sanity and madness. Penguin Books.

Osman, A., Wong, J. L., Bagge, C. L., Freedenthal, S., Gutierrez, P. M., \& Lozano, G. (2012). The Depression Anxiety Stress Scales—21

(DASS-21): Further examination of dimensions, scale reliability, and correlates. Journal of Clinical Psychology, 68(12), 1322-1338. https://doi.org/10.1002/jclp.21908

Smith, M. R., \& Jones, E. T. (1993). Neophobia, ontological insecurity, and existential choice following trauma. Journal of Humanistic Psychology, 33(4), 89-109.

Stoet, G. (2010). PsyToolkit - A software package for programming psychological experiments using Linux. Behavior Research Methods, 42(4), 1096-1104.

Stoet, G. (2017). PsyToolkit: A novel web-based method for running online questionnaires and reaction-time experiments. Teaching of Psychology, 44(1), 24-31.

Wechsler, D (1944). The measurement of adult intelligence. Baltimore: Williams \& Wilkins. ISBN 978-0-19-502296-4. OCLC 219871557. ASIN $=$ B000UG9J7E 


\section{Appendix}

\section{Existential Intelligence Scale}

Please be as honest as you can throughout, and try not to let your responses to one question influence your response to other questions.

1. I actively try to understand my purpose

2. I am fascinated/intrigued when I hear people talk about the meaning of life or if such topics are discussed

3. I often read books or articles or watch videos/lectures on the meaning of life

4. I spend a lot of time thinking about my existence or existence in general and/or its significance

5. I'm attracted to conversations/books/lectures/ or other platforms (podcasts, etc.) that discuss death, dying and the afterlife

6. I often pause while going about my daily life to think about what I'm doing or why I'm doing it

7. I spend a lot of time thinking about what (aspect of me or in general) defines me

8. \{reverse $\}$ I don't find conversations about the universe and our conscious experience of it fascinating or even interesting.

9. I spend a lot of time contemplating whether my existence (and others) is real

10. \{reverse I prefer not to talk or think about death or life after death.

11. I spend a lot of time thinking about the nature of reality and if God exists

12. I often think about the origin of existence 